\title{
The Physiology Effects of a Finnish Sauna on Aerobic Exercise in College-Aged Individuals
}

\author{
Holly Bogdanich ${ }^{1}$, Jan Kiger², Julia Matzenbacher dos Santos ${ }^{3}$
}

\begin{abstract}
Sauna baths acutely increases vasodilation, heart rate (HR) and muscle relaxation; therefore sessions of sauna have been tested as a therapeutic treatment for cardiovascular diseases and psychological diseases. When combined with exercise, sauna baths have been performed to accelerate exercise recovery, with the sauna being done post workout the majority of times. The aim of this study was to determine the effects of the sauna used prior to a bout of moderate intensity aerobic exercise. Eight volunteer performed a 20-minute treadmill aerobic exercise (running) $70 \%$ of maximal VO2 with and without a visit to the sauna. Systolic and diastolic blood pressure (BP), HR, and Rate of Perceived Exertion (RPE) were recorded before, halfway at 10 minutes, and after the aerobic exercise. Systolic BP, assessed before exercise, was not different when subjects performed prior sauna ( $124.8 \pm 10.8$ vs. $125 \pm 11 \mathrm{~mm} / \mathrm{Hg}$ no sauna and sauna, respectively). However, diastolic BP was lower in no-sauna condition vs. sauna condition while HR and RPE ( $73 \pm 5$ vs $80 \pm 4.5 \mathrm{~mm} / \mathrm{Hg} B P, 90 \pm 13 \mathrm{vs}$. $101 \pm 11$ beats/min and 6 vs. 7 RPE no sauna and sauna, respectively). When the comparison was made within the experimental condition exercise, sauna attenuated the increase in systolic and diastolic BP induced by exercise without affecting HR and RPE. Extreme high temperatures experienced in sauna modulate cardiovascular system responses by increasing HR and diastolic blood pressure. Moderate exercise increases systolic and diastolic BP, which might be attenuated when sauna is performed prior to exercise. A Sauna session might be used to modulate the response of exercise towards BP.
\end{abstract}

Keywords: Sauna. Aerobic exercise. Blood pressure. Heart rate. Rating of perceived exertion.

\section{RESUMO}

Uma sessão de sauna pode aumentar de forma aguda a vasodilatação e a frequência cardíaca (FC) e induzir relaxamento muscular; portanto, estudos vem investigando o efeito de sessões de sauna como tratamento terapêutico para doenças cardiovasculares e psicológicas. Quando combinado com exercício, sessões de sauna são realizados para acelerar a recuperação ao exercício, sendo feita após o treino na maioria das vezes. O objetivo deste estudo foi determinar os efeitos da sauna quando usada antes de uma sessão de exercício aeróbico de intensidade moderada. Oito voluntários realizaram uma sessão de exercício aeróbico em esteira de 20 minutos (corrida) a 70\% do VO2 máximo com e sem uma visita à sauna antes do exercício. A pressão arterial sistólica e diastólica (PAS e PAD), a FC e a taxa de esforço percebido (EPR) foram registradas antes, aos 10 minutos e após o exercício aeróbico. A PAS avaliada antes do exercício não foi diferente quando os indivíduos realizaram sauna $(124,8 \pm 10,8$ vs. $125 \pm 11 \mathrm{~mm} / \mathrm{Hg}$ sem sauna e sauna, respectivamente). No entanto, a PAD foi menor na condição de não sauna vs. condição de sauna, enquanto FC e EPR não se modificou ( $73 \pm 5$ vs $80 \pm 4,5 \mathrm{~mm} / \mathrm{Hg} P A, 90 \pm 13$ vs. $101 \pm 11$ batimentos/min e 6 vs. 7 RPE sem sauna e sauna, respectivamente). Quando a comparação foi feita entre as etapas do experimento de condição, a sessão de sauna atenuou o aumento da PAS e PAD induzida pelo exercício sem afetar a FC e o EPR. Sessões de sauna modulam as respostas do sistema cardiovascular aumentando a FC e a pressão arterial diastólica. $O$ exercício moderado aumenta a PAS e PAD, que pode ser atenuada quando a sauna é realizada antes do exercício. Uma sessão de sauna pode ser usada para modular a resposta do exercício em relação à pressão arterial.

Palavras-chave: Sauna. Exercício aeróbico. Pressão sanguínea. Frequência cardíaca. Classificação do esforço percebido.

RECEBIDO EM: 29/5/2019

MODIFICAÇÕES REQUERIDAS EM: 25/8/2019

ACEITO EM: 4/11/2019

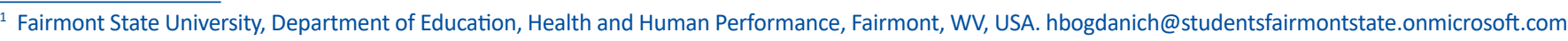
2 Fairmont State University, Department of Education, Health and Human Performance, Fairmont, WV, USA. jkiger1@fairmontstate.edu

${ }^{3}$ PhD. Fairmont State University, Department of Education, Health and Human Performance, Fairmont, WV, USA. Fairmont State University- Department of Education, Health and Human Performance, 1201 Locust Avenue, Fairmont, WV 26554. jdossantos@fairmontstate.edu. jumatzsantos@gmail.com
} 


\section{INTRODUCTION}

For centuries, people have used saunas in beauty spas and fitness centers mainly for stress relief, weight loss and enhancing detoxification (SUTKOWY et al., 2014; SUDAKOV; SINITCHKIN; KHASANOV, 1988). As a result of the extremely high temperature of the sauna, around $70^{\circ} \mathrm{C}$, the body sweats, blood circulation and heart rate (HR) increases (SUTKOWY et al., 2014; SUDAKOV; SINITCHKIN; KHASANOV, 1988; PILCH et al., 2014). In fact, several outcomes of sauna are very similar to aerobic exercise, which attracted the attention of scientists in different fields (SUTKOWY et al., 2014; PODSTAWSKI et al., 2015; HUSSAIN; COHEN, 2018).

There is extensive evidence that sauna baths acutely increase the endurance of the cardiorespiratory and locomotor systems, promote vasodilation and muscle relaxation, in addition to promoting psychological effects (PODSTAWSKI et al., 2015; HUSSAIN; COHEN, 2018). Therefore sessions of sauna have been tested as a therapeutic treatment for cardiovascular diseases and psychological diseases (GAYDA et al., 2012). When combined with exercise, sauna baths have been performed to accelerate exercise recovery, with the sauna being done post workout the majority of times (PAOLONE et al., 1980; SHARMAN; STOWASSER, 2009).

There is, however, limited evidence of the bo$d y$ 's response to sauna bathing before exercise instead of practicing after exercise as the means of a post workout. Therefore it is hypothesized, that the practice of sauna bathing prior to exercise will affect body responses to exercise namely blood pressure, heart rate, and Rate of Perceived Exertion (RPE). The aim of this study was to determine the effects of the sauna used prior to a bout of moderate intensity aerobic exercise.

\section{METHODS}

Subjects: Eight volunteer men and women aged 18 to 24 years old were randomly chosen from students who attend Fairmont State University in Fairmont, West Virginia. The participants were asked to not change their daily diet or physical activities during the course of the study. It was ensured that every participant was healthy and had no constraints for participating in physical activity. Before the participants for this study were selected or data was collected, the study was approved by the Institutional Review Board
(IRB). Once approved by IRB, all subjects were informed about the purpose of the study and informed consents were acquired from all subjects in this study.

Instruments: This study used Fairmont State University's Finnish Sauna, stethoscope, blood pressure cuff, and a Matrix Landice treadmill.

Procedures: This study was a cross-sectional study that consisted of three days. The first day, participants performed Bruce Protocol Treadmill Test to establish the VO2 max and to estimate the intensity of exercise on the following days. The second day (no sauna) the subjects performed a 20-minute treadmill aerobic exercise (running) 70\% of max VO2 without a visit to the sauna. The third day (pre-sauna) the subjects were placed into a sauna room before aerobic exercise for a time period of 15 minutes. The sauna temperature was kept constant at $75^{\circ} \mathrm{C}$ with a relative humidity of $50-60 \%$, while the room where exercise was performed was $22^{\circ} \mathrm{C}$. Systolic and diastolic blood pressure (BP), HR, and RPE (using Bohr's 6 to 20 scale) were recorded before, halfway at 10 minutes, and after the aerobic exercise. Mean of diastolic and systolic BP was quantified. The subjects were asked not to take any supplements, be under any diet or physical activity restrictions.

Analysis: Statistical analyses were performed using SPSS-statistical software (IBM SPSS- statistics 18). Dependent T-Test was used to compare data between exercise with and without sauna. One-way Anova and Tukey test was performed to determine statistical significant difference within conditions. $\mathrm{P}<0.05$ were assumed to be statistically significant. Data are represented as average \pm standard deviation.

\section{RESULTS}

Prior to the beginning of the experiment, maximum VO2 from all participants (age $21 \pm 1.1$ years old) was measured and the correct intensity for the experiment, $70 \%$ of the VO2 max, was estimated (Table 1 ). Systolic and mean of systolic and diastolic BP, assessed before exercise, was not different when subjects performed prior sauna (124.8 \pm 10.8 vs. $125 \pm 11 \mathrm{~mm} / \mathrm{Hg}$ systolic $B P$ and $99 \pm 13$ vs. $100 \pm 11 \mathrm{~mm} / \mathrm{Hg}$ mean $B P$, no sauna and sauna, respectively). However, diastolic BP was lower in no-sauna condition vs. sauna condition ( $73 \pm 5$ vs $80 \pm 4.5 \mathrm{~mm} / \mathrm{Hg}$, Figure 1B). During exercise, halfway, systolic BP remained similar in both conditions while diastolic was higher when subjects performed sauna prior to exercise ( $76 \pm 6$ vs $82 \pm 4 \mathrm{~mm} / \mathrm{Hg}$ ) (Figure 1B). At the end of exercise protocol, no changes were observed either in systolic or diastolic BP 
between the conditions (Figure $1 \mathrm{~A}$ and $1 \mathrm{~B}$ ). When the comparison was made within the experimental condition exercise, sauna attenuated the increase in systolic $B P$ induced by exercise (Figure 1A). Indeed, diastolic $\mathrm{BP}$ and the mean between systolic and diastolic BP, which also increased during exercise when sauna was not performed, was unchanged when sauna was done before exercise (Figure 1B and 1C).

Changes in HR and RPE between conditions were observed only prior to exercise, whereas subjects that performed sauna had an increased HR $(90 \pm 13$ vs. $101 \pm 11$ beats/min) and RPE (Figure $2 \mathrm{~A}$ and $2 \mathrm{~B}$ ). No changes were observed halfway and after exercise between no-sauna vs. performing sauna after exercise. When the comparison was made within the experimental condition, exercise promotes an increase in $\mathrm{HR}$, as anticipated. Moreover, performing sauna prior to the aerobic exercise did not affect the increase in $\mathrm{HR}$ and RPE induced by exercise (Figure $2 \mathrm{~A}$ and $2 \mathrm{~B}$ ).

Table 1 - Subjects age, maximal and 70\% oxygen uptake (VO2 Max) expressed in milliliter per kilogram per minute. Data are expressed as mean \pm standard deviation

\begin{tabular}{cccc}
\hline & $\begin{array}{c}\text { Age } \\
\text { (years old) }\end{array}$ & $\begin{array}{c}\text { VO2 Max } \\
\text { (ml/Kg/min) }\end{array}$ & $\begin{array}{c}70 \% \text { of VO2 Max } \\
\text { (ml/ } / \mathrm{Kg} / \mathrm{min})\end{array}$ \\
\hline \hline Subjects & $20.9 \pm 1.1$ & $58.9 \pm 7.6$ & $40.7 \pm 4.8$ \\
\hline
\end{tabular}

Figure 1 - Systolic (A) and Diastolic (B) blood pressure (BP), and mean of BP (C) measured before exercise, during exercise (halfway- 10 minutes) and after 20 minutes of aerobic exercise (running) without sauna or after 15 minutes of sauna (sauna). ${ }^{*} p<0.05$ compared to no sauna, $\# p<0.05$ compared to before exercise no sauna

A.

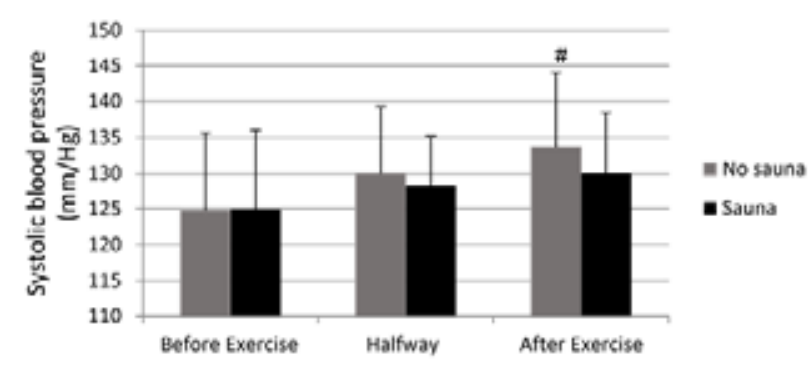

B.

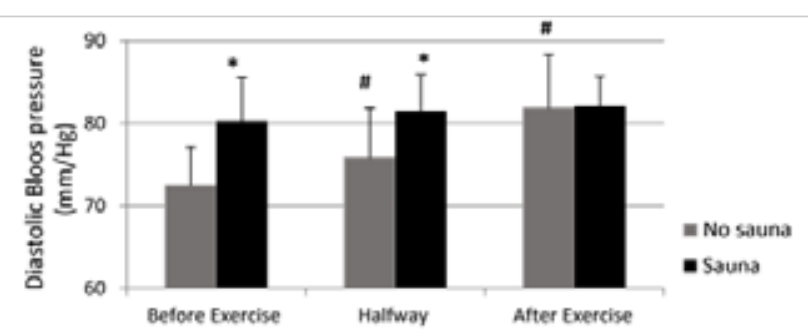

C.

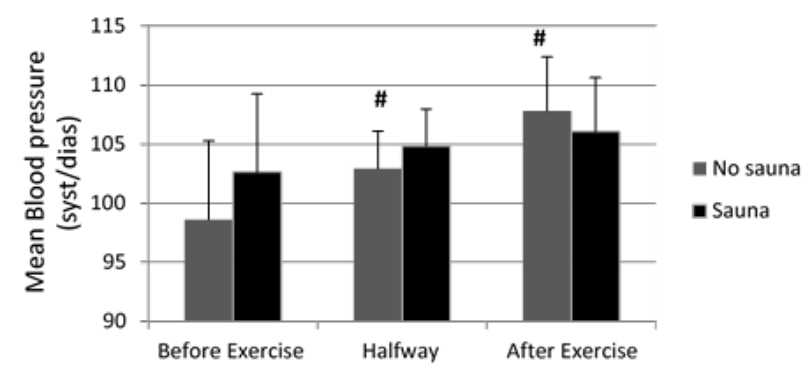

Figure 2 - Heart rate $(A)$ and Rate of Perceived Exertion (RPE) (B) blood pressure (BP) measured before exercise, during exercise (halfway- 10 minutes) and after 20 minutes of aerobic exercise (running) without sauna or after 15 minutes of sauna (sauna). * $p<0.05$ compared to no sauna

A.

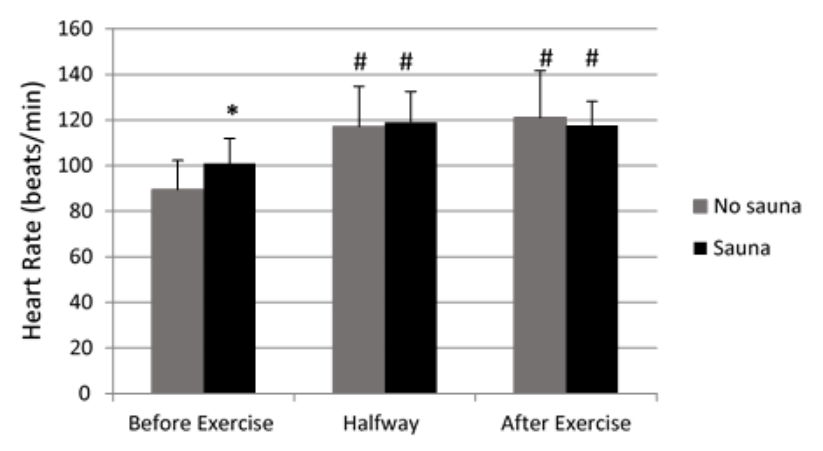

B.

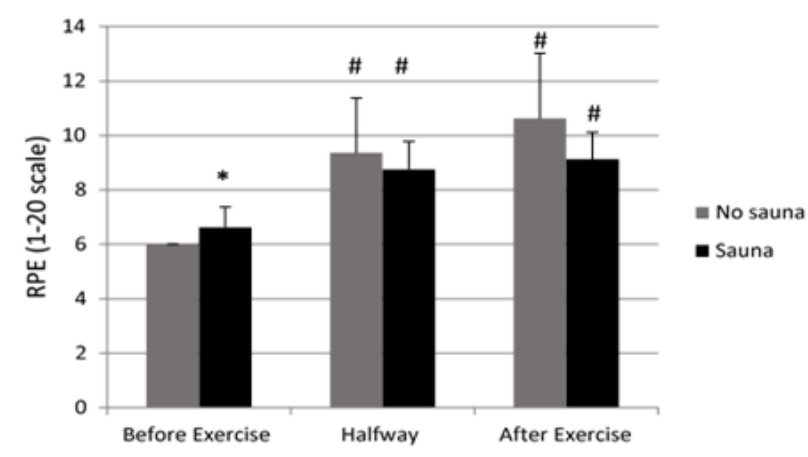

\section{DISCUSSION}

Over the past years several studies have shown the acute and chronical benefits of the heat therapy of the Finnish sauna (PODSTAWSKI et al., 2015; HUSSAIN; COHEN, 2018). In the present study, we sought to determine the effects of Finnish sauna prior to moderate intensity aerobic exercise in young-adult individuals. Our major findings were that an acute session of Finnish sauna does not affect systolic blood pressure, however, induces an increase in diastolic blood pressure and that attenuates changes on diastolic 
blood pressure observed during exercise. Also, a session of sauna promotes increase in HR without affecting the increase on HR and the RPE induced by aerobic exercise.

A session of sauna results in relevant increases in endothelium-dependent dilatation, blood flow and reduction in arterial stiffness and wall thickness affecting blood pressure (HUSSAIN; COHEN, 2018). Taking advantage of changes in the circulatory system, medical professionals have been using sauna for therapeutic treatment of hypertension and cardiovascular diseases. In patients with hypertension or with coronary heart disease, both systolic and diastolic BP has been found to be unchanged or decreased during and shortly after sauna (SIEWERT, 1994; LUURILA; KOHVAKKA; SUNDBERG, 1989). These findings opposed the present study probably due to the population studied. While our studied population included healthy normotensive young-adults, other studies observed the effect of sauna in patients with cardiovascular conditions (hypertension, coronary heart disease).

The mechanism of cardiovascular adaptation has been shown after exposure of sauna. A single bout of sauna was shown to decrease the parasympathetic and/or enhanced sympathetic system which could be observed by an increase in HR (KUKKONEN-HARJULA et al., 1989). This effect was also observed in the present study since HR increased after sauna that is in agreement of what was shown after wet sauna. Increase in RPE and HR are indicators of changing in body homeostasis and both were upregulated after sauna, which indicate that the protocol of 15 minutes of heat therapy was enough to promote physiological changes in the body.

Combined exercise and heat protocols using sauna are usually performed with elite athletes post-exercise (CASADIO et al., 2017). Exposing athletes to extreme temperatures such as those experienced during saunas may provide them with a time-efficient method to stimulate physiological adaptations that could contribute to improved performance (STANLEY et al., 2015). Few studies analyzed the effect of the combination of exercise and sauna, and in most of them sauna was performed after exercise by people with hypertension and cardiovascular disease (GAYDA et al., 2012, SHARMAN et al., 2009). In cardiac rehabilitation facility it was shown that systolic blood pressure decreased after the combination of exercise pre-sauna when compared to control (no intervention) and sauna alone (GAYDA et al., 2012). Diastolic blood pressure was unaffected in Gayda et al. (2012) study. Paolone and colleagues (1980), compared post-exer- cise sauna BP with post-exercise BP alone, and sauna was responsible for decrease diastolic blood pressure. Here we demonstrated that a sauna session attenuated changes in BP (systolic, diastolic and mean) induced by exercise without affecting the increase in HR and the stability of RPM. In agreement, an increase in blood pressure during aerobic exercise was reported previously (PALATINE et al., 1998). Exercise induces a great number of beneficial physiological responses namely for people suffering from cardiovascular disease (DOS SANTOS et al., 2015; DOBROSIELSKI et al., 2017; RIBEIRO et al., 2016). The increase in BP is, however, an unwanted response for people with hypertension therefore a short session of sauna prior aerobic exercise might help to control BP during exercise. Nevertheless, the effect of sauna prior to exercise in hypertensive people was not tested.

In summary, extreme high temperatures experienced in sauna modulate cardiovascular system responses by increasing HR and diastolic blood pressure. Moderate exercise increases systolic and diastolic BP, which might be attenuated when sauna is performed prior to exercise. A Sauna session might be used to modulate the response of exercise towards BP.

\section{REFERENCES}

CASADIO, J. R. et al. From Lab to Real World: Heat Acclimation Considerations for Elite Athletes. Sports Med., 2017 Aug; 47(8):1467-1476. doi: 10.1007/s40279-016-0668-9.

DOBROSIELSKI, D. A. et al. Diet and exercise in the management of obstructive sleep apnoea and cardiovascular disease risk. Eur Respir Rev., 26 (144). pii: 160110, Jun. 2017. DOI: 10.1183/16000617.0110-2016.

DOS SANTOS, J. M. et al. The effect of exercise on skeletal muscle glucose uptake in type 2 diabetes: An epigenetic perspective. Metabolism, 64(12), p. 1.619-1.628, Dec. 2015. DOI: 10.1016/j.metabol.2015.09.013.

GAYDA M. et al. Effects of sauna alone and postexercise sauna baths on blood pressure and hemodynamic variables in patients with untreated hypertension. J Clin Hypertens, Greenwich, 14(8), p. 553-560, Aug. 2012. DOI: 10.1111/j. 1751-7176.2012.00637.x.

HUSSAIN J.; COHEN, M. Clinical Effects of Regular Dry Sauna Bathing: A Systematic Review. Evid Based Complement Alternat Med., 2018. 1857413. Published 2018 Apr 24. DOI: $10.1155 / 2018 / 1857413$.

KUKKONEN-HARJULA, K. et al. Haemodynamic and hormonal responses to heat exposure in a Finnish sauna bath. Eur J Appl Physiol Occup Physiol., 58, p. 543-550, 1989.

LUURILA, O. J.; KOHVAKKA, A.; SUNDBERG, S. Comparison of blood pressure response to heat stress in sauna in young hypertensive patients treated with atenolol and diltiazem. Am J Cardiol., 64, p. 97-99, 1989. 
PALATINI, P. Blood pressure behaviour during physical activity. Sports Med., 5(6), p. 353-74, Jun. 1988. Review. PubMed PMID: 3041529.

PAOLONE, A. M. et al. Effects of a postexercise sauna bath on ECG pattern and other physiologic variables. Aviat Space Environ Med., 51, p. 224-229, 1980.

PILCH, W. et al. (2014). Comparison of physiological reactions and physiological strain in healthy men under heat stress in dry and steam heat saunas. Biology of Sport, 31(2), p. 145-149, 2014. DOI:10.5604/20831862.109904.

PODSTAWSKI, R. et al. (2015). The influence of socioeconomic and psychological factors on the popularity of sauna treatment among female university students. Baltic Journal of Health \& Physical Activity, 7(2), p. 67-82, 2015. Available from: https://ezproxy.fairmontstate.edu/login?urI=https://search.ebscohost.com/login.aspx?direct=true\&$\mathrm{db}=\mathrm{s} 3 \mathrm{~h} \& A N=116295198 \&$ site=ehost-live \&scope=site. $\quad$ Cited: 5 Oct. 2018).

RIBEIRO, S. A. B. et al. Association between blood pressure, body mass index, eating habits, and physical activity in adolescents. Scientia Medica, 26, p. 8-14, 2016.
SHARMAN, J. E.; STOWASSER, M. Australian association for exercise and sports science position statement on exercise and hypertension. J Sci Med Sport., 12, p. 252-257, 2009.

SIEWERT, $C$. The behavior of central and peripheral hemodynamics in isometric and dynamic stress in hypertensive patientstreatment with regular sauna therapy. Z Kardiol., 83, p. 652-657, 1994.

STANLEY, J. et al. Effect of sauna-based heat acclimation on plasma volume and heart rate variability. Eur J Appl Physiol. 2015 Apr; 115(4):785-94. doi: 10.1007/s00421-014-3060-1. SUDAKOV, K. V.; SINITCHKIN, V. V.; KHASANOV, A. A. Systemic Responses in Man Exposed to Different Heating and Cooling Treatment in a Sauna. The Pavlovian Journal of Biological Science, 23(3), p. 89-94, 1988. DOI: 10.1007/ BF02701280.

SUTKOWY, P. et al. The effect of a single Finnish sauna bath after aerobic exercise on the oxidative status in healthy men. Scandinavian Journal Of Clinical And Laboratory Investigation, 74(2), p. 89-94, 2014. DOI: 10.3109/00365513.2013.860616. 